\title{
Outbreak of tuberculosis among substance users and homeless people in Greater Montréal, Canada, 2003-2016
}

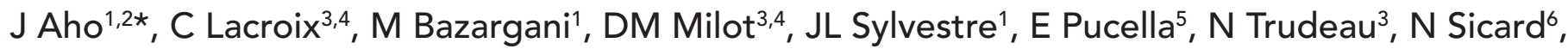 \\ N Savard ${ }^{1}, 7$, P Rivest $^{1}$, H Soualhine $^{8}$, M Munoz-Bertrand ${ }^{1}$
}

\begin{abstract}
Background: In Canada, active tuberculosis (TB) is found mainly among migrants from endemic countries and Indigenous populations. However, cases of active tuberculosis in substance users and homeless persons have been reported in Greater Montréal since 2003.
\end{abstract}

Objective: To describe the Montréal TB outbreak in terms of the sociodemographic characteristics, risk factors and clinical characteristics of cases, as well as the intensity of public health interventions, the follow-up and identification of locations of potential transmission.

Methods: All cases of active tuberculosis with the same genotype of interest residing in Quebec and epidemiologically linked cases were included in the analysis. Data were retrospectively extracted from routine public health investigations. Characteristics of cases were summarized using Excel. Spatial analysis of locations frequented during cases' infectiousness periods was performed.

Results: Between January 2003 and February 2016, a total of 35 cases were identified. Most (86\%) were non-Indigenous people born in Canada. Of these, 28 had several risk factors, including substance use (93\%), alcohol abuse (64\%), homelessness (46\%), comorbidities such as HIV coinfection (36\%) and advanced stage of the disease. Seven cases without risk factors were all close contacts of cases. Intensity of case management by public health authorities was high. Locations frequented by cases with risk factors included crack houses, shelters and rehabilitation centres in Montréal's downtown core and a residential setting in a suburban area.

Conclusion: TB outbreaks can occur in marginalized Canadian-born urban populations, especially those with substance use. Tailored interventions in this population may be needed for screening, and earlier identification of both latent and active TB and better linkage to care.

Suggested citation: Aho J , Lacroix C, Bazargani M, Milot DM, Sylvestre JL, Pucella E, Trudeau N, Sicard N, Savard N, Rivest $P$, Soualhine H, Munoz-Bertrand M. Outbreak of tuberculosis among substance users and homeless people in Greater Montréal, Canada, 2003-2016. Can Commun Dis Rep. 2017;43(3):72-6.

https://doi.org/10.14745/ccdr.v43i34a03

\author{
Affiliations \\ ${ }^{1}$ Direction régionale de \\ santé publique du Centre \\ intégré universitaire de santé \\ et de services sociaux du \\ Centre-Sud-de-l'Île-de-Montréal, \\ Montréal, QC \\ ${ }^{2}$ Canadian Field Epidemiology \\ Program, Public Health Agency of \\ Canada, Ottawa, ON \\ ${ }^{3}$ Direction de santé publique \\ du Centre intégré de santé \\ et de services sociaux de la \\ Montérégie-Centre, Longueuil, \\ QC \\ ${ }^{4}$ Faculté de médecine et des \\ sciences de la santé, Université de \\ Sherbrooke, Sherbrooke, QC \\ ${ }^{5}$ Direction de santé publique du \\ Centre intégré de santé et de \\ services sociaux de Laval, Laval, \\ QC \\ ${ }^{6}$ Direction de la protection de la \\ santé publique, Ministère de la \\ Santé et des Services sociaux du \\ Québec, Montréal, QC \\ ${ }^{7}$ Department of Epidemiology, \\ Biostatistics and Occupational \\ health, McGill University, \\ Montréal, QC \\ ${ }^{8}$ Laboratoire de santé \\ publique du Québec, \\ Sainte-Anne-de-Bellevue, QC
}

*Correspondence: josephine.aho. ccsmt|@ssss.gouv.qc.ca

\section{Introduction}

Tuberculosis (TB) is a major driver of morbidity and mortality in the world. In 2015, there were an estimated 10.4 million new cases of active TB disease and 1.8 million TB deaths (1). Canada is among the countries with the lowest incidence of $T B$, reaching an all-time low of 4.4/100,000 in 2014 (2,3). As in most low-incidence countries, TB is concentrated in specific groups-mainly Indigenous populations and migrants from endemic countries. However, outbreaks have been reported in Vancouver, Toronto, Edmonton and Ottawa as well as in several US cities, typically among groups with overlapping risk factors, such as HIV/AIDS coinfection, homelessness, substance use and incarceration (2-11). While data on incidence rates of active TB in these groups are scarce, an incidence of 13.2/100,000 person-year has been reported among the homeless in Montréal (7).

With an overall active TB incidence of 2.9/100,000 in 2014, Quebec has the lowest incidence rates of TB in the country after the Maritime provinces (3). Between 2008 and 2011, 62.7\% of cases were identified in migrants, $25.3 \%$ in Canadian-born non-Indigenous people and $10.1 \%$ in Canadian-born Indigenous people (12). Most cases were from the Greater Montréal area (12).

All active TB cases are reportable by law in Quebec, and treatment of active TB is mandatory, with regional public health departments able to take legal measures to ensure compliance 
with treatment (13). After a case is reported by a physician or a laboratory, the public health department initiates an investigation to trace and test contacts and follows up with the patient until treatment is completed.

In 2003, a few cases of active TB disease were linked to the same community-based organization. Later, more patients from underprivileged neighborhoods in Montréal and surrounding areas were identified with active TB disease, with the same genotype and similar risk factors, such as drug use and homelessness. This marked the start of an outbreak that is still ongoing.

The objective of this article is to describe this TB outbreak in terms of the sociodemographic characteristics, risk factors and clinical characteristics of cases as well as the intensity of public health interventions and the follow-up and identification of locations of potential transmission.

\section{Methods}

\section{Case identification}

In this retrospective population-based investigation, we included all active and confirmed TB cases with the available genotype of interest who were living in the province of Quebec at the time of diagnosis and all probable cases epidemiologically linked to the confirmed cases. Confirmed cases were identified through Mycobacterial interspersed repetitive units - variable number of tandem repeats (MIRU-VNTR) typing or restricted fragment length polymorphism (RFLP). The genotype of interest was an identical 11-band RFLP and the same 12-loci MIRU or the same 24-loci MIRU after 2006 when this technology was available. These specific 12-loci and 24-loci MIRU define the same strain. All Mycobacterium tuberculosis strains were cultured and identified at the Laboratoire de santé publique du Québec (LSPQ). The 24-locus MIRU-VNTR genotyping (14) is performed routinely by the National Microbiology Laboratory as part of a collaboration project with the LSPQ since 2012 (although genotyping was performed on a case-by-case basis before 2012).

\section{Data collection}

Each regional public health department extracted data collected through their routine case investigations and follow-up files. Anonymized data from Montréal, Laval and Montérégie were pooled for analysis by the Direction régionale de santé publique du Centre intégré universitaire de santé et de services sociaux du Centre-Sud-de-l'Île-de-Montréal (Montréal Public Health).

Variables of interest included sociodemographic characteristics, risk factors, clinical characteristics, follow-up and intensity of public health intervention as well as locations visited during the infectiousness period. Information about risk factors of interest-substance use, alcohol and tobacco consumption, sex work, homelessness, incarceration in the previous two years, comorbidities such as prior episode(s) of active TB, HIV or hepatitis $\mathrm{C}$ coinfection and mental health issues-were routinely collected through public health investigation. Clinical characteristics included site of infection, symptoms, test results (chest X-ray and smear positivity), hospitalization, treatment and clinical outcomes. Variables related to public health intervention and follow-up included use of legal measures, such as isolation orders or court orders and intensity of public health intervention. Average intensity of public health interventions during the full course of follow-up was appraised using an ordinal scale designed with public health nurses. The scale was based on the average number of interventions (such as phone calls, visits, etc., to the patient or a health professional in relation to the case) required to complete the investigation, and to ensure compliance regarding isolation and treatment. The scale had four levels of intervention: low (less than one intervention every 4-6 weeks), normal (one intervention every 4-6 weeks), high (one intervention every 2-3 weeks) or very high (one or more interventions per week).

Locations visited by infectious patients collected during case investigation to trace contacts were retrieved from patient files. The infectious periods were estimated for pulmonary and laryngeal TB cases and defined in accordance with provincial and Canadian guidelines $(13,14)$. The period of infectiousness ended when patients were placed in isolation, the standard care for contagious cases.

\section{Data analysis}

Descriptive statistics were obtained using Excel 2010 (Microsoft Corp, Redmond, WA). Patients were stratified into two groups depending on whether they displayed at least one risk factor. Unadjusted proportions and means were presented. For patients who had two episodes of TB with the same MIRU pattern (three cases), only the first episode was included in the descriptive analysis because data for second episodes were frequently missing.

Spatial analysis of the locations patients went to during their infectious periods and the spatial aggregation of these locations was performed. All of the locations visited by patients while contagious were included.

\section{Results}

Between January 2003 and February 2016, 35 people met the case definition of this outbreak in three contiguous regions of Quebec: Montréal (21 cases), Montérégie (12 cases) and Laval (two cases). Of these, 29 confirmed cases had the same genotype and six probable cases were epidemiologically linked to cases with this genotype. Three cases had two episodes of active TB with the same MIRU resulting profile for a total of 38 episodes. Two of those cases with a second episode were HIV positive.

Figure 1 displays the epidemic curve for this outbreak. Although there were only eight cases in seven years between 2003 and 2009, the number of cases tripled to 27 from 2010 to 2016.

\section{Sociodemographic characteristics}

The age of patients ranged between 1 and 69 years (median 37; interquartile range 33-47); $57 \%$ were men. Most (30/35; 86\%) were non-Indigenous people born in Canada; three (9\%) were Inuit, one (3\%) was a non-Inuit Indigenous person and one (3\%) was foreign-born. 
Figure 1: Outbreak of tuberculosis in Montréal, Montérégie and Laval, 2003-2016

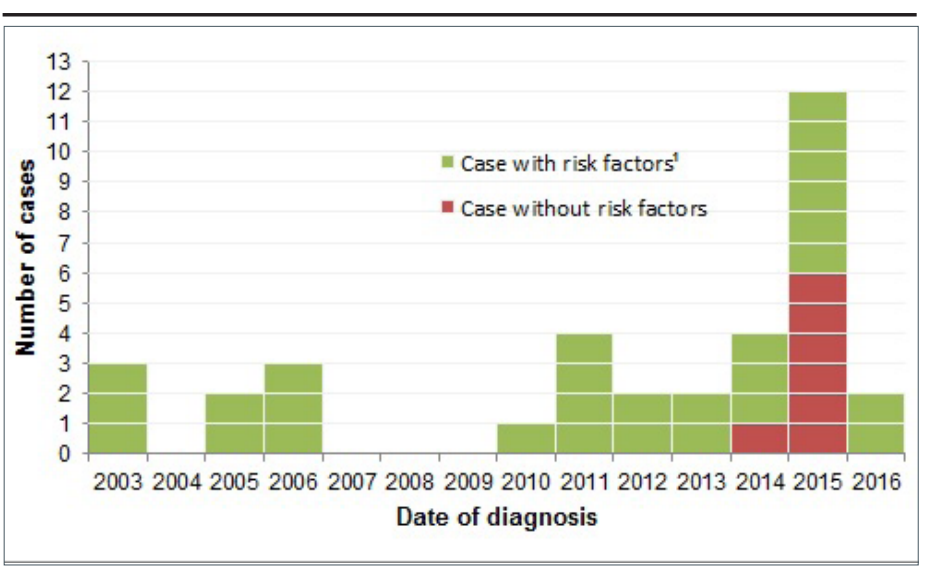

See Table 1 for type and prevalence of risk factors

\section{Risk factors}

Cases were classified in two groups: with risk factors $(n=28)$ and without $(n=7)$. The cases without risk factors were all close contacts (such as family members) of two of the cases with risk factors; four were children under 12 years of age. All of the cases (except one) without risk factors occurred in 2015 and represented half of the cases diagnosed that year (Figure 1).

All cases with risk factors had more than one risk factor. The most common risk factor was substance use (93\%), in particular cocaine (54\%) and crack (39\%) use. Missing data were frequent for some risk behaviours (such as intravenous or heroin drug use, tobacco use and sex work) and mental health issues (Table 1).

Table 1: Frequency of risk factors among cases who had one or more risk factors ${ }^{1}(n=28)$

\begin{tabular}{|l|r|r|r|}
\hline \multicolumn{1}{|c|}{ Risk factors } & $\begin{array}{r}\text { Number (\%) } \\
\text { of cases with } \\
\text { this risk factor }\end{array}$ & $\begin{array}{c}\text { Number (\%) of } \\
\text { cases without } \\
\text { this risk factor }\end{array}$ & $\begin{array}{c}\text { Number } \\
\text { (\%) of cases } \\
\text { with missing } \\
\text { values }\end{array}$ \\
\hline Substance use & $26(93)$ & $0(0)$ & $2(7)$ \\
\hline Cocaine & $15(54)$ & $3(11)$ & $10(36)$ \\
\hline Heroin & $3(11)$ & $5(18)$ & $20(71)$ \\
\hline Crack & $11(39)$ & $2(7)$ & $15(54)$ \\
\hline Intravenous drug use & $7(25)$ & $5(18)$ & $16(57)$ \\
\hline Tobacco use & $15(54)$ & $1(3)$ & $12(43)$ \\
\hline Alcohol abuse & $18(64)$ & $2(7)$ & $8(29)$ \\
\hline Sex work & $10(36)$ & $6(21)$ & $12(43)$ \\
\hline Mental health disorders & $8(29)$ & $5(18)$ & $15(54)$ \\
\hline Hepatitis C coinfection & $12(43)$ & $11(39)$ & $5(18)$ \\
\hline Homelessness & $13(46)$ & $15(54)$ & $0(0)$ \\
\hline HIV coinfection & $10(36)$ & $14(50)$ & $4(14)$ \\
\hline $\begin{array}{l}\text { Non-HIV } \\
\text { immunosuppression }\end{array}$ & $5(18)$ & $18(64)$ & $5(18)$ \\
\hline Prior incarceration & $8(29)$ & $12(43)$ & $8(29)$ \\
\hline
\end{tabular}

Abbreviations: $n$, number; \%, percentage

Some do not equal $100 \%$ due to rounding to nearest decimal

\section{Clinical characteristics}

The most frequent site of active TB disease was the lung (30/35; $86 \%)$; five cases had disseminated TB $(5 / 35 ; 14 \%)$. Three patients died before treatment completion, including two who were HIV-positive. Causes of death were substance overdose $(n=1)$, cancer $(n=1)$ and unknown cause that may have been related to TB $(n=1)$. The median age of cases with risk factors was 40 years old (range: $27-57)$. The median age of cases without risk factors was 12 years old (range: 1-69). Table 2 presents the frequency of other clinical characteristics and outcomes of cases by risk factor status.

Table 2: Sociodemographic and clinical characteristics of cases by risk factor status ${ }^{1}$

\begin{tabular}{|c|c|c|}
\hline Variables & $\begin{array}{l}\text { Number }(\%) \text { of } \\
\text { cases with } 1+\text { risk } \\
\text { factor(s) }(n=28)\end{array}$ & $\begin{array}{l}\text { Number }(\%) \text { of } \\
\text { cases without risk } \\
\text { factors }(n=7)\end{array}$ \\
\hline \multicolumn{3}{|l|}{ Sex } \\
\hline Female & $12(43)$ & $3(43)$ \\
\hline Male & $16(57)$ & $4(57)$ \\
\hline \multicolumn{3}{|l|}{ Site of infection ${ }^{2}$} \\
\hline Pulmonary & $24(86)$ & $6(86)$ \\
\hline Disseminated & $5(18)$ & 0 \\
\hline Laryngeal & $1(4)$ & 0 \\
\hline Other & $3(11)$ & 1 (14) \\
\hline Symptomatic & $26(93)$ & $4(57)$ \\
\hline \multicolumn{3}{|l|}{ Chest $\mathrm{X}$-ray findings } \\
\hline Normal & $1(4)$ & $1(14)$ \\
\hline Abnormal non-cavitary & $11(39)$ & $5(71)$ \\
\hline Cavitary lesions & $12(43)$ & $1(14)$ \\
\hline \multicolumn{3}{|l|}{ Sputum smear } \\
\hline Negative & $2(7)$ & $6(86)$ \\
\hline 1+ positivity & $6(21)$ & 0 \\
\hline $2+$ positivity & $5(18)$ & 0 \\
\hline $3+$ positivity & $4(14)$ & $1(14)$ \\
\hline 4+ positivity & $6(21)$ & 0 \\
\hline \multicolumn{3}{|l|}{ Clinical outcome } \\
\hline Cured & $22(79)$ & $7(100)$ \\
\hline Still under treatment & $2(7)$ & 0 \\
\hline Lost to follow-up & $1(4)$ & 0 \\
\hline Deceased & $3(11)$ & 0 \\
\hline
\end{tabular}

Cases with risk factors were almost all symptomatic (93\%), had advanced disease with X-rays showing cavities (43\%), disseminated TB (18\%), and high sputum smear positivity (3+ to $4+, 10 / 28 ; 35 \%)$. Consequently, median duration of hospitalization for cases with risk factors was 38 days (range: 0-571 days) and the median duration of treatment nine months (range: 6-32 months). For cases without risk factors, the median duration of hospitalization was 0 days (range: $0-6$ days) and the median duration of treatment six months (range: 6-7 months). Most cases $(29 / 35,83 \%)$ were cured after treatment completion. No antimicrobial resistance before or during the course of treatment was observed (including for cases without risk factors). Cases without risk factors seemed to have less advanced 
diseases and included three asymptomatic cases that were diagnosed through contact tracing.

\section{Intensity of public health intervention}

There were several factors that lead to a high intensity of public health interventions. In some cases, presentation to health care professionals occurred only when people were at an advanced stage of disease. This meant there had been a long period of infectiousness prior to diagnosis and treatment. This elicited extended contact tracing interventions that uncovered additional cases. Overall, infectiousness lasted between 0.5 and 18.9 months (median: 4 months).

There were also challenges during treatment. Due to medication and isolation compliance issues, eight public health orders and eight court orders were issued to nine patients (26\%), mostly to those with risk factors $(8 / 9 ; 89 \%)$. Frequency of intervention by public health nurses was high or very high for 22 cases with risk factors (79\%) and for one case without risk factor (14\%).

\section{Spatial analysis}

Although places frequented by cases were distributed across Montréal, Montérégie and Laval, other locations attended were concentrated in specific hot spots. Shelters, other non-governmental organizations as well as places attended for sex work, recreation and drug use were concentrated in a particular area of downtown Montréal and included the crack houses visited by several cases (map not shown to respect privacy). Spatial analysis of aggregation identified two main hot spots $(P<0.05)$ : an underprivileged area of downtown Montréal and a residential area in Montérégie.

\section{Discussion}

This outbreak investigation shows that TB outbreaks occur in marginalized Canadian-born urban populations, especially among those who are substance users and homeless. The predominant risk factor is substance use, especially crack and cocaine use. Other comorbidities, such as HIV coinfection and mental health issues, were not uncommon. Of concern was the finding that the outbreak had spread to close contacts who had no risk factors other than exposure.

In this outbreak, the number of cases, disease severity, periods of infectivity, comorbidities and disease evolution, were similar to those in previous studies conducted in Montréal (1996-2007) and in BC $(5,7)$. The high rate of HIV coinfection might explain, in part, the advanced stage of active disease and the high number of cases in these populations, as reactivation of latent TB infection is more likely in the immunocompromised (14). Damage to the respiratory tract caused by crack smoking may also contribute to the acquisition and evolution of the disease.

A number of factors might explain the ongoing transmission and duration of this 13-year outbreak. Homeless people, illicit substance users and sex workers often lack health insurance documentation, experience stigma and have competing priorities related to basic needs or substance use that may hinder access to health and social services. This can result in either no health care or delayed presentation for care. In addition, since active TB is relatively rare, clinicians might not consider this diagnosis in non-migrant/non-Indigenous patients. This constellation of factors may have also been at play in other extended outbreaks, an 8-year-long outbreak in British Columbia (6) and a 17-year-long outbreak in Toronto (9). In a review of source patient characteristics at the origin of 26 outbreaks between 2002 and 2011, profiles of high infectivity, social risk factors (alcohol and drug use, homelessness and incarceration) and delay in diagnosis such as those observed in this Montréal outbreak were very frequent (15). Unfortunately, the multiple overlapping risk factors and the long duration of treatment was associated with labour-intensive case management, a high level of public health intervention and frequent use of legal measures. Intensive case management also occurred in a similar outbreak in Toronto (4).

Our spatial analysis confirmed previous reports that identified drug use sites as a potential area for transmission (7). A specific area of downtown Montréal is known as a hot spot for drug use with numerous crack houses (16). These are not easy locations for mass screening given the setup, rules and context (17). We also identified a suburban area in the Montérégie linked to one particularly contagious case, possibly identifying a new pattern of substance use that takes place mainly in residential settings (18). Shelters or rehabilitation centers were also visited by several cases over time as reported in Edmonton, where transmission was clearly associated with a small number of shelters (8).

Designing and conducting successful TB control interventions in marginalized urban populations is challenging. Active case-finding in shelters and other community-based organizations between 2013 and 2015 did not identify any new cases, yet additional cases were later found. Concerted efforts continue and include spatial analysis, a new social network questionnaire, public health alerts to clinicians and systematic screening in specific locations. The mobility of this population reinforces the importance of coordination between regions, community organizations and substance use treatment services.

This study had several limitations. First, it used retrospective data to describe risk factors that are routinely but not consistently collected or reported. The questionnaire for case investigation changed over time and varied between regions leading to frequent missing data. Second, we did not report on contact tracing as this information was often difficult to obtain. Third, we used places frequented during the period of infectiousness as proxies of places of transmission. No information was available on places visited when the cases acquired their infection. Some potential locations of transmission were difficult to elicit and some might have been missed. Lastly, some cases linked to the outbreak may have been missed, especially before 2012 when systematic MIRU-VNTR of TB strains began in Quebec. Although 24 loci MIRU-VNTR genotyping offers a high discriminatory power, in rare instances, strains with the same MIRU pattern may not be linked (19).

\section{Conclusion}

Although migrants from endemic countries and Indigenous populations remain at highest risk of active TB in Canada, TB outbreaks linked to substance use (especially crack and cocaine) and homelessness occur in urban areas. Marginalized urban people who are substance-users have been identified as a 
high-risk group worldwide. This outbreak indicates that a high index of suspicion is needed to detect TB in this population, especially if HIV is present.

\section{Acknowledgements}

We would like to thank all the public health nurses from the three regions for their valuable help in reviewing the cases and extracting data. We also acknowledge the contribution of the Laboratoire de santé publique du Québec and from staff at the National Reference Centre for Mycobacteriology of the National Microbiology Laboratory (Public Health Agency of Canada) for strains characterization and genotyping. We would like to thank André Bilodeau from the Direction régionale de santé publique du Centre intégré universitaire de santé et de services sociaux du Centre-Sud-de-l'île-de-Montréal for his help in data extraction and Robert Allard from the same institution and Eric Levac from the Direction de santé publique du Centre intégré de santé et de services sociaux de la Montérégie-Centre for help revising this manuscript.

\section{Conflict of interest}

None.

\section{Contributions}

JA - Conceptualization, Data extraction and analysis, Writing - original draft, review and editing, $\mathrm{CL}-$ Conceptualization, Investigation, Data extraction, Writing - Review and Editing, MB - Conceptualization, Spatial analysis, Writing - Review and Editing, DMM Conceptualization, Data extraction, Writing - Review and Editing, JLS - Conceptualization, Investigation, Data extraction, Writing - Review and Editing, EP - Conceptualization, Data extraction, Writing - Review and Editing, NT - Conceptualization, Investigation, NSi - Writing - Review and Editing, NSa - Writing - Review and Editing, PR - Investigation, Writing - Review and Editing, HS - Laboratory testing, Writing - Review and Editing, MMB - Conceptualization, Investigation, Data extraction, Writing - original draft, review and editing.

\section{References}

1. Tuberculosis. Fact sheet [Internet]. Geneva: World Health Organization; 2016 [cited 2017 Feb 1]. Available from: http://www. who.int/mediacentre/factsheets/fs104/en/.

2. Towards tuberculosis elimination: an action framework for lowincidence countries [Internet]. Geneva: World Health Organization; 2014 [cited 2016 Dec 20]. 77p. Available from: http://apps.who.int/ iris/bitstream/10665/132231/1/9789241507707_eng.pdf?ua=1.

3. Tuberculosis in Canada 2014 -- Pre-release [Internet]. Ottawa: Public Health Agency of Canada; 2016 [cited 2016 Dec 20]. Available from: https://www.canada.ca/content/dam/canada/health-canada/ migration/healthy-canadians/publications/diseases-conditions- maladies-affections/tuberculosis-2014-tuberculose/alt/tuberculosis2014-tuberculose-eng.pdf.

4. Khan K, Rea E, McDermaid C, Stuart R, Chambers C, Wang J, Chan A, Gardam M, Jamieson F, Yang J, Hwang SW. Active tuberculosis among homeless persons, Toronto, Ontario, Canada, 1998-2007. Emerg Infect Dis. 2011;17(3):357-65. doi: 10.3201/eid1703.100833.

5. Gardy JL, Johnston JC, Ho Sui SJ, Cook VJ, Shah L, Brodkin E, Rempel S, Moore R, Zhao Y, Holt R, Varhol R, Birol I, Lem M, Sharma MK, Elwood K, Jones SJ, Brinkman FS, Brunham RC, Tang P. Wholegenome sequencing and social-network analysis of a tuberculosis outbreak. N Engl J Med. 2011;364(8):730-9. doi: 10.1056/ NEJMoa1003176.

6. Cheng JM, Hiscoe L, Pollock SL, Hasselback P, Gardy JL, Parker R. A clonal outbreak of tuberculosis in a homeless population in the interior of British Columbia, Canada, 2008-2015. Epidemiol Infect. 2015;143(15):3220-6.

7. Tan de Bibiana J, Rossi C, Rivest P, Zwerling A, Thibert L, Mclntosh F, Behr MA, Menzies D, Schwartzman K. Tuberculosis and homelessness in Montreal: a retrospective cohort study. BMC Public Health. 2011;11:833. doi: 10.1186/1471-2458-11-833.

8. Moreau D, Gratrix J, Kunimoto D, Beckon A, Der E, Hansen E, Chui $\mathrm{L}$, Ahmed R. A shelter-associated tuberculosis outbreak: a novel strain introduced through foreign-born populations. Can J Public Health. 2012;103(6):e408-12.

9. Mehaffy C, Guthrie JL, Alexander DC, Stuart R, Rea E, Jamieson FB. Marked microevolution of a unique Mycobacterium tuberculosis strain in 17 years of ongoing transmission in a high risk population. PLoS One. 2014;9(11):e112928. doi: 10.1371/journal.pone.0112928.

10. Bamrah S, Yelk Woodruff RS, Powell K, Ghosh S, Kammerer JS, Haddad MB. Tuberculosis among the homeless, United States, 1994-2010. Int J Tuberc Lung Dis. 2013;17(11):1414-9. doi: 10.5588/ ijtld.13.0270.

11. McAdam JM, Bucher SJ, Brickner PW, Vincent RL, Lascher S. Latent tuberculosis and active tuberculosis disease rates among the homeless, New York, New York, USA, 1992-2006. Emerg Infect Dis. 2009; 15(7):1109-11. doi: 10.3201/eid1507.080410.

12. Rivest $P$, Street $M C$. Épidémiologie de la tuberculose au Québec de 2008 à 2011 [Internet]. Quebec: Agence de la santé et des services sociaux; 2014 [cited 2016 Dec 20]. Available from: http:// publications.msss.gouv.qc.ca/msss/fichiers/2014/14-266-01W.pdf.

13. Rivest $P$, Abdelaziz N, Déry $S$, Isler M, Lacroix $C$, Thibert L. Guide d'intervention pour la tuberculose - Édition 2012 [Internet]. Quebec: Ministère de la santé et des services sociaux; 2013 [cited 2016 Dec XX]. Available from: http://publications.msss.gouv.qc.ca/msss/ fichiers/2012/12-271-01W.pdf.

14. Canadian tuberculosis standards 7th ed. Ottawa: Public Health Agency of Canada; 2014. Available from: http://www.phac-aspc. gc.ca/tbpc-latb/pubs/tb-canada-7/index-eng.php.

15. Haddad MB, Mitruka K, Oeltmann JE, Johns EB, Navin TR Characteristics of tuberculosis cases that started outbreaks in the United States, 2002-2011. Emerg Infect Dis. 2015;21(3):508-10.

16. Leclerc $P$, Fall $A$, Morissette $C$. Estimation de la taille et caractérisation de la population utilisatrice de drogues par injection à Montréal. Direction de santé publique. Montréal: Agence de la santé et des services sociaux de Montréal; 2013. p. 4.

17. Roy E, Arruda N. Exploration of a crack use setting and its impact on drug users' risky drug use and sexual behaviors: the case of piaules in a Montreal neighborhood. Subst Use Misuse 2015;50(5):630-41.

18. Milot DM. Évaluation du besoin et de la pertinence de l'implantation d'un service d'injection supervisée en Montérégie [master's thesis]. Montréal: Université de Montréal; 2014. Available from: https:// papyrus.bib.umontreal.ca/xmlui/handle/1866/11821.

19. Christianson S, Wolfe J, Orr P, Karlowsky J, Levett PN, Horsman GB, Thibert L, Tang P, Sharma MK. Evaluation of 24 locus MIRU-VNTR genotyping of Mycobacterium tuberculosis isolates in Canada. Tuberculosis (Edinb). 2010;90(1):31-8. 